stock by interbreeding, but that it probably emigrated in mass. Since it did not return to the southern (eastern) settlement, or to Iceland, or to anywhere else that we know of, it seems clear that, if FischerMøller is right, which I feel to be most probable, it must have attempted a migration to the American continent itself. In Newfoundland or Labrador, beside the Great Lakes or Hudson Bay, we must look for traces of the Norsemen from West Greenland.

People in Britain must surely feel some pleasure at this conclusion. The dismal picture of decay and failure drawn from the interpretation of the Herjolfsness material is changed to one of expectancy and interest in a new problem. It is changed also to one of almost personal pride, for the examination of the Greenland skulls makes it clear that Celtic blood was strong in the old medieval settlers as it was also in medieval Iceland. When this last expedition rowed out westward over the cold grey waters of Baffin Bay, there were those aboard it who remembered the old tales of Tir nan og and the bright lands beyond the sunset.

T. C. LeThBRIDGE

9)

\section{POPULATION DENSITY OF THE SHEEP BLOWFLY IN AUSTRALIA}

D

ARCY GILMOUR, D. F. Waterhouse and G. A. McIntyr, in appaper entitled "An Account of

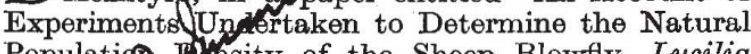
Population IChsity of the Sheep Blowfly, Lucilia cuprin Wed.", have endeavoured to assess the value of tyajping as a means of controlling those insects (Q) Mmonwealth Coun. Sci. Ind. Research, Bull: 195 ; 1946). The method used was that of liberating a known number of marked flies and of sampling by means of traps the population in an area surrounding the point of release. The number of blowflies within the area was then calculated by multiplying the ratio of the unmarked to marked flies caught in the traps by the number of marked flies liberated in the trapping area. Some 102 traps were used, and these were disposed at equal intervals in a circle of 6 miles diameter. Some 40,000 flies were liberated at the centre of this circle one day before the trapping began. The marking of the blowflies was by staining them with an alcoholic solution of suitable dyes. Two treatments were given: the first with an electric power sprayer and the second with a hand atomizer. In the main experiments, the diameter of the circle was increased to 8 miles.

The results of four experiments made between November 1941 and March 1942 showed that the natural blowfly population varied between $0 \cdot 3$ and $5 \cdot 7$ flies per acre. The distribution of the stained flies was found to agree fairly well with a theoretical distribution curve based on the assumption that the flies moved outwards at random. The rate of dispersal of the stained flies varied from one experiment to another, the differences showing some correlation with meteorological conditions.

The error involved in the method of estimating population density was of the order of about 20 per cent. In addition, the possibility that an additional error has to be allowed for cannot be overlooked, since the stained blowflies did not behave exactly as the natural population. There is also a further error arising from the fact that the validity of the method of estimation is based on the assumption that, activity being uniform, the catch of each trap varies directly with the population density. This may not be the case, and there is some evidence that could be interpreted as indicating that the catches of stained flies in the central traps, where the population is high, are disproportionately large. At present the available data are insufficient to evaluate these factors; but the authors consider that the results they obtained give a tolerably reliable estimation of the true fly population. It is noteworthy that an analysis of the variation between the catches of individual traps shows that some of the variability was due to local differences in the natural population.

While the experiments were not designed to record the maximum range of flight, it is worth noting that the greatest distance from the point of release at which flies were taken was $4 \cdot 7$ miles - a distance which they covered in less than 30 hours.

\section{FORESTRY IN SIERRA LEONE}

$\mathrm{W}$ ITH the end of the War has come the task of the switchover from war production to civil requirements jut the forestry services of the EmpireP fy theport on Forest Administration of Sierfa fweone for the Year 1945 (Government Pfint ro Freetown, 1946) we see that this process is 5 ong undertaken, one of the objects being to consebve the natural resources-forests and waterof the country wherever necessary and wherever possible.

The report states-and it has been often repeated in the past for other regions of the world-that the Colony is suffering acutely from the uncontrolled destruction of hill forests by bush and grass fires. It is held that conservation by controlling these two evils is the greatest need in the country to-day, and until it becomes effective, agriculture instead of being a thriving industry will continue its downward trend. Much of the country is already so degraded that only bare subsistence farming is possible, and that for a very short time now. Landslides and floods are becoming a serious menace to property. The cause and effect are apparent and the remedy is obvious. It will take years, says the writer, to rebuild the soil and water resources of the country; but it is possible, when effected, that a stable agriculture will ensue.

The policy of the Forestry Department has been approved by the Development Council and incorporated into the general plan of the country. It lays down a programme of work for the next ten years and provides the basis for more detailed regional planning. It has been framed in accordance with the long-term policy accepted by Government, the two main objectives being the expansion of the conservation programme, and a continuance of forest utilization started during the War, to ensure self-sufficiency in timber. Certain sums of money have been allocated to these two objectives, which are closely related.

As the report definitely states, constant vigilance will be required to ensure that the conservation programme is not sacrificed to utilization, as has been so often the case in the past. During the War, in this and other Colonies, the sacrifice was almost inevitable; but that demand has now ceased, and it should be the aim of the Department that the objects of the ten-year programme be firmly adhered to, and that in every case utilization be made subordinate to the programme of soil conservation. 